\title{
The Transmembrane Inner Ear (tmie) Gene Contributes to Vestibular and Lateral Line Development and Function in the Zebrafish (Danio rerio)
}

\author{
Yu-Chi Shen, ${ }^{1}$ Anandhi K. Jeyabalan, ${ }^{1}$ Karen L. Wu, ${ }^{1}$ Kristina L. Hunker, ${ }^{2}$ David C. Kohrman, ${ }^{2}$ \\ Deborah L. Thompson, ${ }^{1 \dagger}$ Dong Liu, ${ }^{3}$ and Kate F. Barald ${ }^{1 *}$
}

The inner ear is a complex organ containing sensory tissue, including hair cells, the development of which is not well understood. Our long-term goal is to discover genes critical for the correct formation and function of the inner ear and its sensory tissue. A novel gene, transmembrane inner ear (Tmie), was found to cause hearing-related disorders when defective in mice and humans. A homologous tmie gene in zebrafish was cloned and its expression characterized between 24 and 51 hours post-fertilization. Embryos injected with morpholinos (MO) directed against tmie exhibited circling swimming behavior ( $\sim 37 \%)$, phenocopying mice with Tmie mutations; semicircular canal formation was disrupted, hair cell numbers were reduced, and maturation of electrically active lateral line neuromasts was delayed. As in the mouse, tmie appears to be required for inner ear development and function in the zebrafish and for hair cell maturation in the vestibular and lateral line systems as well. Developmental Dynamics 237:941-952, 2008.

๑ 2008 Wiley-Liss, Inc.

Key words: semicircular canals; auditory development; hair cells; Spinner homologue

Accepted 22 January 2008

\section{INTRODUCTION}

The vertebrate inner ear, a complex sense organ responsible for both the detection of sound and the position and motion of the head, is an ideal model system for studies of fundamental developmental mechanisms (Barald and Kelley, 2004). It is derived from bilaterally symmetrical regions of thickened ectoderm that form the otic placodes, which in most verte- brates invaginate, but cavitate in zebrafish to form the hollow otic vesicle. The otic vesicle contains nearly all of the cells that comprise the mature inner ear (Barald and Kelley, 2004; Fritzsch et al., 1997; Torres and Giraldez, 1998), including the auditory organ (cochlea in mammals), vestibular organs (semicircular canals, sacculus, and utricle), and the ganglion cells that innervate these organs. Both au- ditory and vestibular organs contain sensory hair cells (HCs), which are specialized receptor cells that sense mechanical energy through the action of actin filament-rich projections known as stereocilia, on their apical surfaces. Deflection of stereocilia increases the open state of ion channels, depolarizing the hair cell and initiating action potentials in ganglion cells and subsequent propagation of the

\footnotetext{
The Supplementary Material referred to in this article can be viewed at http://www.interscience.wiley.com/jpages/1058-8388/suppmat ${ }^{1}$ Department of Cell and Developmental Biology and Department of Biomedical Engineering, University of Michigan Medical School, Ann Arbor, Michigan

${ }^{2}$ Departments of Human Genetics and Otolaryngology, University of Michigan Medical School, Ann Arbor, Michigan

${ }^{3}$ Institute of Neuroscience, University of Oregon, Eugene, Oregon

Grant sponsor: DRF; Grant sponsor: NIH; Grant numbers: NIH DC05939, NIH DC04184, NIH DC003049, T32 DC00011; Grant sponsor:

Indiana University Medical School; Grant number: RO1 DC006436 (subcontract to U.M.).

${ }^{\dagger}$ Deborah L. Thompson's present address is Department of Internal Medicine, Division of Pulmonary and Critical Care Medicine, University of Michigan, Ann Arbor, MI

*Correspondence to: Kate F. Barald, Ph.D., Department of Cell and Developmental Biology, 3053 BSRB 2200, 109 Zina Pitcher Place, Ann Arbor, MI, 48109-2200. E-mail: kfbarald@umich.edu
}

DOI 10.1002/dvdy.21486

Published online 10 March 2008 in Wiley InterScience (www.interscience.wiley.com). 
signal to higher-level nuclei in the central nervous system.

In humans, 50-60\% of hearing losses have a genetic origin. In the past decade, as many as 45 genes associated with hearing loss have been identified (Eisen and Ryugo, 2007). These genes include non-conventional myosins (myosins VIIa, XVa, VI, and III), which are found in HC stereocilia and may play roles in synaptic vesicle movements as well as mechanoelectric transduction (Piatto et al., 2005); cadherin 23 and harmonin, which are associated with myosin VIIa, and are involved in stereociliar organization (Friedman and Griffith, 2003); KCNQ1 and KCNQ4, voltage-gated potassium channels (Strutz-Seebohm et al., 2006); connexins 26, 30, and 31, components of gap junctions found in the inner ear; and claudin14, a component of tight junctions in the cochlea (Piatto et al., 2005). The genetic causes of human vestibular dysfunction are less well understood. To date, only two genes that are associated with genetic hearing loss have been found to be associated with balance problems in humans: Myosin VIIa and $\mathrm{COCH}$, which encodes the cochlin protein, a major component of the extracellular matrix of the inner ear (Kerber, 2006). However, in mouse mutants, defects in the vestibular system are often associated with deafness and because they are more severe, they are more easily diagnosed (Avraham and Raphael, 2003).

A few years ago, we reported that recessive mutations in the Tmie gene cause vestibular dysfunction and profound hearing loss in spinner (sr) mice (Mitchem et al., 2002). Although no defects in gross inner ear morphogenesis were observed in affected $s r$ mice, mutants exhibited early postnatal defects in sensory cell maturation, including a failure to maintain organized stereociliar bundles; later, degeneration of sensory and ganglion cells was seen (Mitchem et al., 2002). In addition to the inner ear, Tmie is also expressed in the brain, liver, kidney, and lung (Mitchem et al., 2002). Subsequent genetic studies indicated that mutations in the human ortholog of mouse Tmie are responsible for congenital, profound hearing loss in families segregating defects at the
DFNB6 locus on chromosome 3 (Naz et al., 2002; Santos et al., 2006).

In this study, we have identified a zebrafish ortholog of the mammalian Tmie gene and found expression of tmie in the developing inner ear as well as other tissues. Inner ear development in zebrafish follows a broadly similar plan to that found in other vertebrates, although some morphological patterning processes differ. According to Whitfield (2000, 2002) and Bever and Fekete (2002), development of the inner ear in zebrafish begins with an ectodermal thickening on either side of the hindbrain, which forms the otic placode. Development of the otic placode begins at the 14somite stage, which is around $16 \mathrm{hr}$ post-fertilization (hpf), but pre-patterning happens earlier (Novince et al., 2003). The otic vesicle and otoliths develop at $19 \mathrm{hpf}$ and $22 \mathrm{hpf}$, respectively. The placode then cavitates to create the otic vesicle, in contrast to placodal invagination, which is seen in most other vertebrates. Thickened regions of developing sensory epithelium consist of an arrangement of sensory hair cells and underlying supporting cells as in other vertebrates. Two maculae, the rostral patch (utricular) with a vestibular role and the caudal (saccular) sensory macula with an auditory role, develop first and each is covered by an otolith. The development of these maculae is followed by the formation of three cristae that later become part of the three semicircular canals (Haddon and Lewis, 1996). The third macular organ, the lagena, does not form until later, during the juvenile stage (Nicolson, 2005). In zebrafish, a cochlear structure does not develop. Growing hair cells have formed by the time the otic vesicle cavitates at $18 \mathrm{hpf}$.

As otic vesicles form, hair cell kinocilia secure the otoliths in place (Platt, 1993; Babb-Clendenon et al., 2006). At $42 \mathrm{hpf}$, thickened otic vesicle walls are noted under Nomarski optics, and the semicircular canals of the ear develop by $48 \mathrm{hpf}$. Between 3 to 7 days, the numbers of hair cells in each macula increase. By the end of the first week, all the key components of the ear are present (Haddon and Lewis, 1996). Although zebrafish develop slightly differently from other vertebrates and do not possess a mammalian cochlear or- gan, patterns of gene expression parallel those seen in mammals and the zebrafish is an excellent model system in which to study developmental processes relating to hearing and deafness (Whitfield, 2002; Barald and Kelley, 2004). An additional advantage of using the zebrafish as a model is that they also have sensory receptors on the body surface, the lateral line neuromasts, which structurally and functionally resemble inner ear sensory patches (Whitfield, 2005).

Using antisense morpholino oligonucleotides (MOs) directed against tmie, we demonstrate that tmie morphants exhibit vestibular dysfunction and defective maturation of sensory cells in the inner ear and lateral line. Our studies suggest a conserved function of tmie in sensory cell development across vertebrate species.

\section{RESULTS}

\section{The Zebrafish tmie Gene}

Using bioinformatic analysis and RTPCR, we have identified a zebrafish cDNA corresponding to the likely ortholog of the mammalian Tmie genes. The zebrafish gene is composed of four coding exons, with the positions of introns in the zebrafish gene similar to those found in mammalian Tmie (Fig. $\mathrm{S} 1$, which can be viewed at http://www interscience.wiley.com/jpages/1058-8388/ suppmat). The predicted protein encoded by the zebrafish cDNA exhibits $55 \%$ amino acid identity and $65 \%$ similarity to the mouse Tmie protein and contains two putative transmembrane domains at positions similar to those predicted in mammalian Tmie proteins (Fig. 1B; Mitchem et al., 2002). The highest sequence conservation is found in the regions encoded by exons 2 and 3 , encompassing a predicted extracellular domain, the second transmembrane domain, and the juxtamembrane region, which is the site in the human Tmie protein of missense mutations associated with hearing loss (Naz et al., 2002). The zebrafish protein is larger (222 amino acids) than the mouse (153 aa) and human (156 aa) Tmie proteins. We have identified a gene in the Fugu genome that encodes a similarly large protein ( 223 aa) with $64 \%$ identify and $72 \%$ similarity to the zebrafish protein. The size increase in the fish pro- 
A

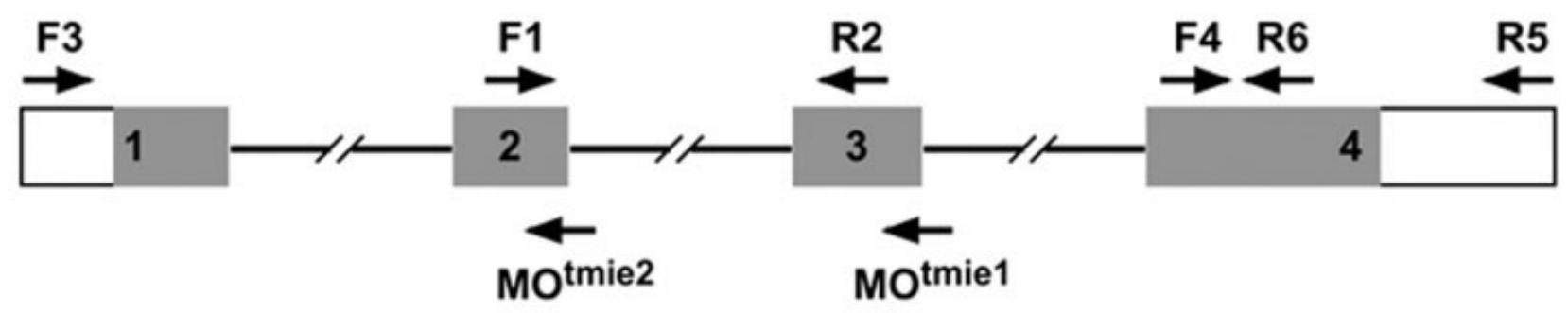

B
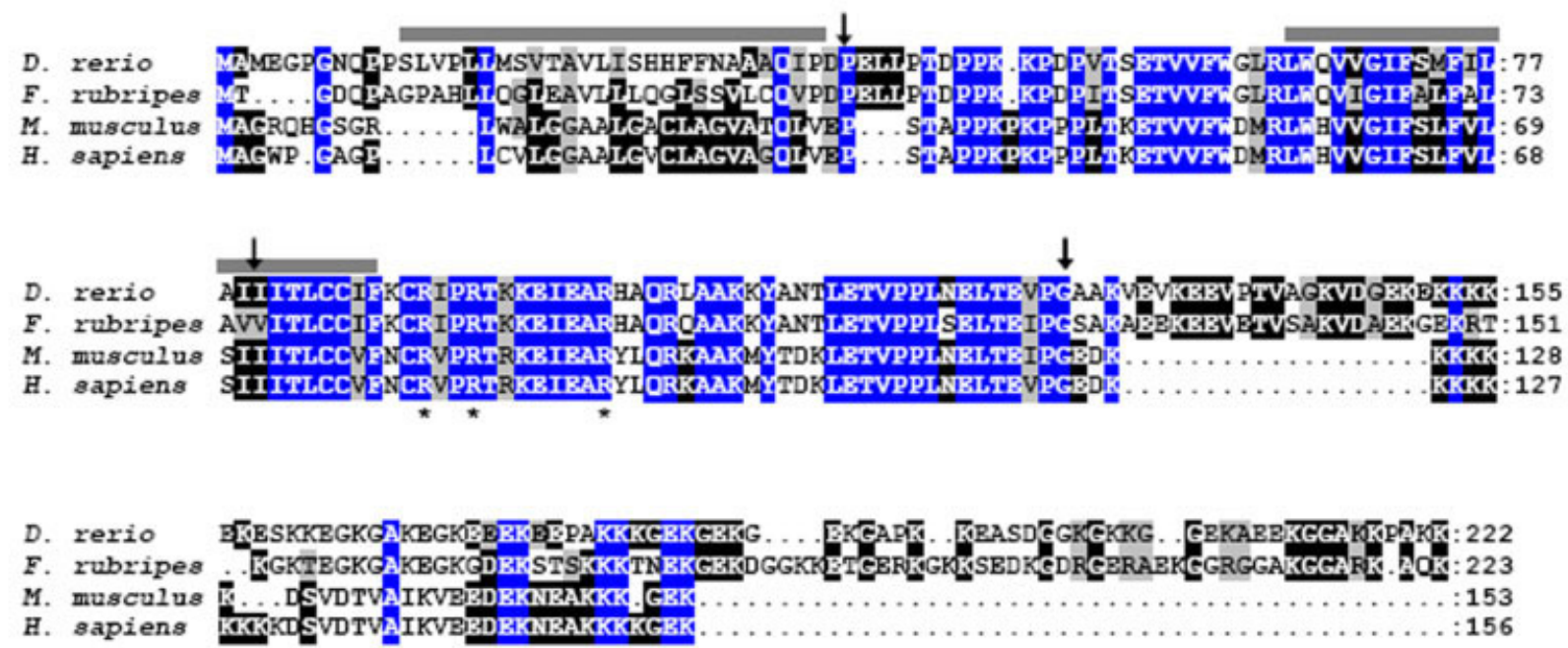

Fig. 1. Tmie proteins are conserved across vertebrate species. A: Zebrafish tmie gene structure and the positions of the primers used to obtain the sequence of tmie cDNA. The positions of MOtmie1 and MOtmie2 are also shown. Gray boxes indicate the open reading frame for the predicted tmie protein, and the white boxes indicate the untranslated regions. B: Alignment of Tmie proteins from four species is shown. Positions that exhibit amino acid identity across all four species are shaded in blue. Positions that are identical in at least two species are shaded in black. Positions with biochemically similar residues are shaded in gray. Bars indicate predicted transmembrane domains. Asterisks indicate arginine residues that are altered in humans with hearing loss due to mutations at the DFNB6 locus (Naz et al., 2002). Arrows indicate the positions of exon junctions in the corresponding genes.

teins is due to extended C-terminal regions, which retain the highly charged character of the mammalian Tmie proteins. The arginine residues in the juxtamembrane region that are altered by mutation in humans with hearing loss are also present in the fish proteins, consistent with a critical, conserved role in protein function. The zebrafish gene is located on chromosome 2, near pthr1, similar to the physical linkage of mammalian Tmie genes with Pthr1 (Mitchem et al., 2002). This conserved synteny, together with the strong conservation of sequence and structure with the mammalian genes, supports this gene as the zebrafish tmie ortholog.

\section{Expression Patterns of tmie}

By RT-PCR analysis, tmie transcript was not detected at $12 \mathrm{hpf}$, but was first detected at $26 \mathrm{hpf}$, and subsequently at 38 and $54 \mathrm{hpf}$ (Fig. 2A). Expression patterns of tmie were also examined in zebrafish by ISH at 26 , 36 , and $51 \mathrm{hpf}$ using a probe derived from the coding sequence of tmie. Control embryos treated with sense probes had no specific ISH staining (Fig. 2C,E,G). Microscopic analysis demonstrated that 26-hpf fish treated with the antisense probes showed specific, although not robust, labelling in the brain and the developing otic vesicle (Fig. 2B). A similar labelling pattern was detected in the otic vesicle at later stages (Fig. 2D and F), while signal in the brain was reduced at $36 \mathrm{hpf}$ (Fig. 2D) and was undetectable at 51 hpf (Fig. 2F). It should be noted that a similar lack of robust expression characterizes the mouse gene (Hunker et al., unpublished data). These results indicate that although its transcript is present at low levels, tmie probably plays a role in both inner ear and brain development in zebrafish.

\section{Morpholino Injections}

Morpholino injections were performed to observe phenotypic differences when expression of full-length tmie was reduced. Two tmie morpholinos were used in the analysis. Injection of $\mathrm{MO}^{\text {tmie1 }}$, which is directed against the splice donor site of exon 3 , resulted in an increase in tmie transcripts lacking exon 3 and a corresponding decrease in normal transcripts (Fig. 3A). Transcripts lacking exon 3 encode a truncated protein that lacks a portion of the predicted second transmembrane region and the juxtamembrane domain, the site of missense mutations in humans with hearing loss. Injection 
A

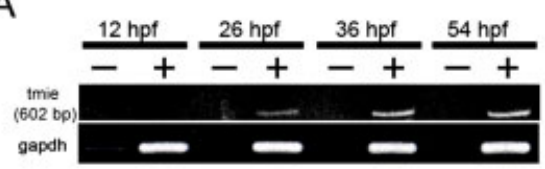

B
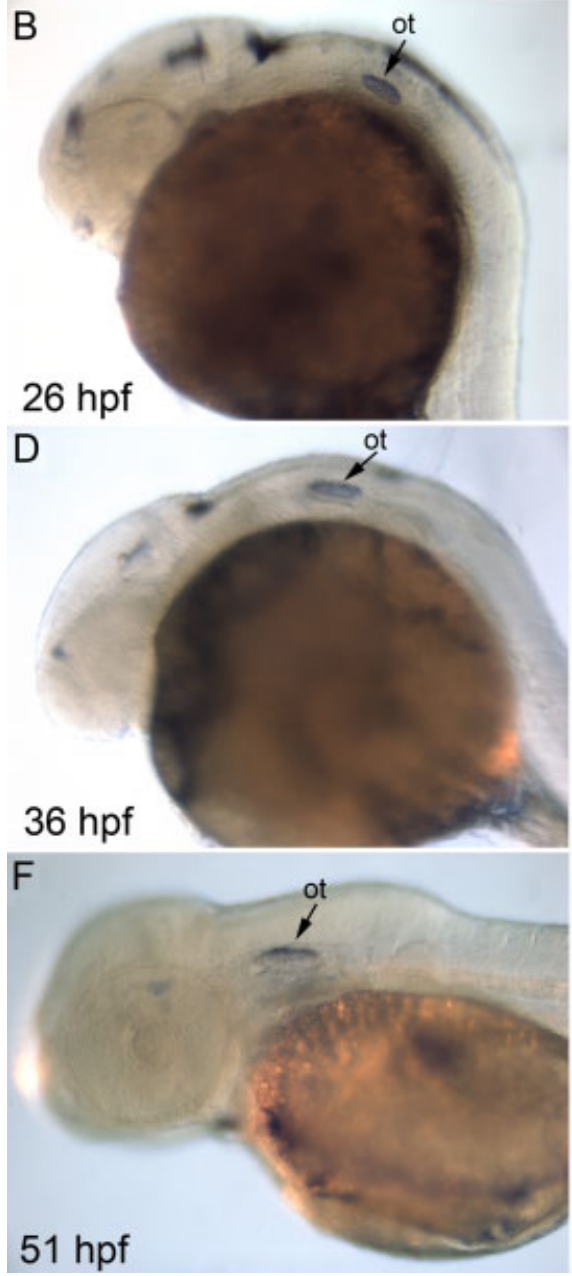

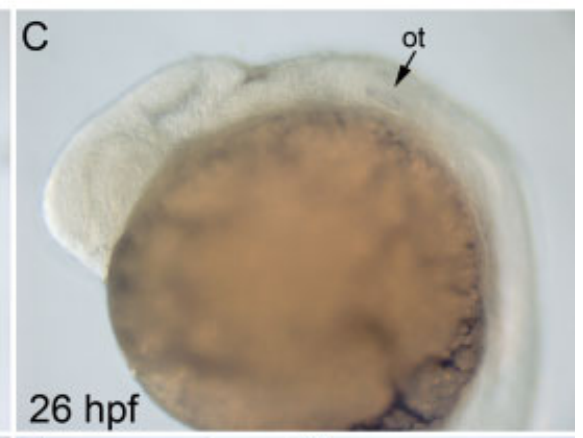

E

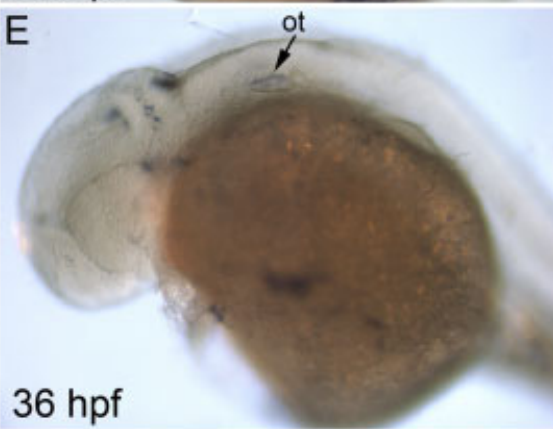

G

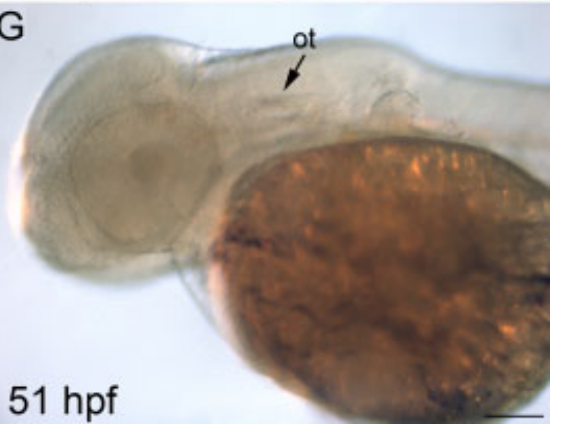

Fig. 2. Expression of tmie mRNA in the brain, and ear. A: RT-PCR results from various stages of embryonic development: -, no reverse transcriptase; +, with reverse transcriptase. B,C: Lateral view of 26-hpf embryos with tmie antisense probe (B) and sense probe (C). D,E: Lateral view of 36-hpf embryos with tmie antisense probe (D) and sense probe (E). F,G: Lateral view of 51-hpf embryos with tmie antisense probe (F) and sense probe (G). Signals were found in the developing otic vesicle at all stages observed. There is also staining in the brain. ot, otic vesicle; sc, spinal cord. Scale bar $=100 \mu \mathrm{m}$.

of $\mathrm{MO}^{\text {tmie2}}$, which is directed against the splice donor site of exon 2 , resulted in a decrease in normal transcripts (Fig. 3B). Shortened transcripts lacking exon 2 were not identified, presumably due to activation of nonsense-mediated decay by the frameshift and nonsense codons that were introduced by exon skipping. Fish injected with the tmie morpholinos were compared to those injected with a Gene Tools Standard Control morpholino at the same total concentration. The effects of both MOs on the transcripts were still observed at 72 hpf (data not shown).

Most of the initial experiments were done with $\mathrm{MO}^{\text {tmie1 }}$. Many of the experiments were subsequently repeated with $\mathrm{MO}^{\text {tmie2}}$, and eventually experiments were done with a combination of the two MOs with lower doses (2.5 $\mu \mathrm{g} / \mu \mathrm{l})$ of each in the combined injection mix. Observations took place at $24 \mathrm{hpf}, 48 \mathrm{hpf}$, and 3-6 dpf with morphological and behavioral differences noted beginning after $24 \mathrm{hpf}$. Compar-
A

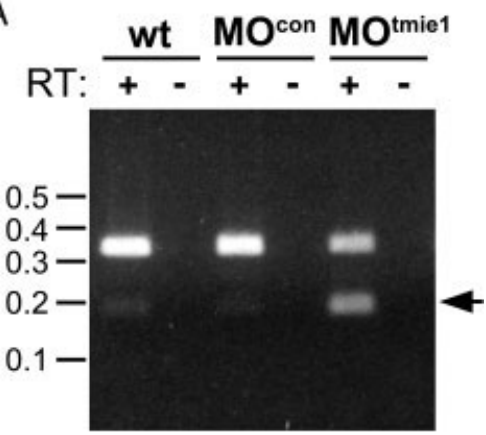

B

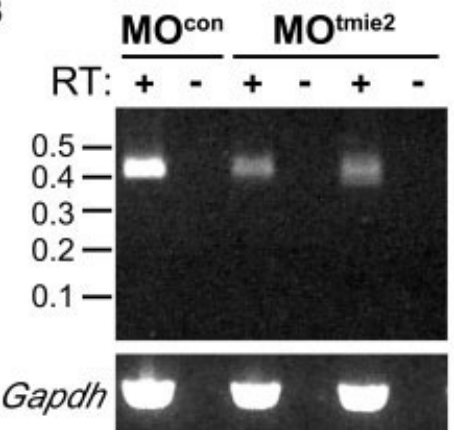

Fig. 3. Morpholinos directed against tmie decrease levels of normal transcripts. A: Injection of an anti-tmie morpholino (MOtmie1) directed against the splice donor site of exon 3 resulted in a decreased level of intact transcripts and a substantial increase in shorter tmie transcripts that lacked exon 2 (arrow) at 36 hpf. Very little of the shorter transcript was detected at $36 \mathrm{hpf}$ in uninjected embryos (wt) or in embryos injected with a control morpholino (MOcon). B: Injection of an anti-tmie morpholino (MOtmie2) directed against the splice donor site of exon 2 resulted in decreased levels of intact tmie transcripts at 36 hpf (products amplified from two independent RNA preparations are shown), relative to those present in embryos injected with a control morpholino. Levels of Gapdh transcripts are shown in the bottom panel. Size standards are indicated in $\mathrm{kb}$.

isons were based on movement, swimming behavior, the size of the ear and eye, as well as expression patterns of genes that are normally expressed in the developing inner ear, hindbrain, and periotic mesenchyme at this time (data not shown; also see below).

Table 1 shows the morphology and touch response of embryos at $24 \mathrm{hpf}$. At this stage, at least one smaller ear was observed in about $40 \%$ of embryos injected with $\mathrm{MO}^{\text {tmie1 }}$. More than half of these had both ears smaller than the control-injected embryos (control MO) with only one otolith in each. The doses used $(2.5 \mu \mathrm{g} / \mu \mathrm{l}$ and $3.5 \mu \mathrm{g} / \mu \mathrm{l})$ did not differentially affect the percentage of fish with (a) smaller ear(s). However, there is a dose-dependent 
TABLE 1. General Morphology and Touch Response of the Embryos at 24 hpf $^{\text {a }}$

\begin{tabular}{lll}
\hline & At least one & At least one \\
$24 \mathrm{hpf}$ & smaller ear $(\%)$ & Failure to respond \\
smaller eye $(\%)$
\end{tabular}

aThe percentage is the average of 3 experiments for $2.5-\mu \mathrm{g} / \mu \mathrm{l}$ morpholino injections, and 2 experiments for $3.5-\mu \mathrm{g} / \mu \mathrm{l}$ injections; "smaller" mean less than or equal to half the size of the eye or ear in the control fish.

effect of $\mathrm{MO}^{\text {tmie1 }}$ on the size of the eyes. Smaller eyes were observed in twice the number of embryos treated with the higher dose $(3.5 \mu \mathrm{g} / \mu \mathrm{l})$ of $\mathrm{MO}^{\text {tmie1 }}$ as the lower dose (Table 1). Most of the control embryos responded to tail touch by moving the body, while a quarter of tmie morphants failed to move after being touched, and those fish that did respond spontaneously darted for only short distances and stopped.

We further tested the swimming behavior and balance at later stages. A behavioral assessment test was performed at $96 \mathrm{hpf}$ to evaluate reorientation of fish in a Petri dish after swirling. While almost all control embryos oriented perpendicular to the periphery of the dish after swirling, an average of $40 \%$ of tmie morphants with $2.5 \mu \mathrm{g} / \mu \mathrm{l} \mathrm{MO}^{\text {tmie } 1}$ and $45 \%$ of embryos with $3.5 \mu \mathrm{g} / \mu \mathrm{l} \mathrm{MO} \mathrm{M}^{\text {tmie } 1}$ treatment remained in the middle of the dish and did not reorient themselves by swimming to the edge (Fig. $4 \mathrm{~A}, P<$ 0.05). Of those that failed the swirl test, most of them swam in circles. The averages of morphants swimming in circles is $30 \%(2.5 \mu \mathrm{g} / \mu \mathrm{l})$ and $40 \%$ (3.5 $\mu \mathrm{g} / \mu \mathrm{l}) \mathrm{MO}^{\text {tmie1 }}$ treatment, compared to 0 and $3 \%$ swimming in circles with control MO treatments at these concentrations (Fig. 4A, $P<0.005$ ).

Motor coordination of the embryos injected with a combination of $\mathrm{MO}^{\text {tmie1 }}$ and $\mathrm{MO}^{\text {tmie2 }}\left(\mathrm{MOs}^{\text {tmie }}\right)$ was tested from 3 to $6 \mathrm{dpf}$. Over $85 \%$ of control larvae developed motor coordination and swam rapidly across a $10-\mathrm{cm}$ Petri dish in a straight line (Kwak et al., 2006) at 5 dpf. Only $33 \%$ of $\mathrm{MO}^{\text {tmie } 1}$ morphants exhibited this level of swimming ability (Fig. 4B). Most morphants with $\mathrm{MOs}^{\text {tmie }}$ swam in a circle even at $6 \mathrm{dpf}$. However, MO ${ }^{\text {tmie } 1}$ morphants acquired motor coordination at
4 and 5 dpf compared to the control larvae, and finally $95 \%$ of $\mathrm{MO}^{\text {tmie1 }}$ morphants achieved motor coordination at $6 \mathrm{dpf}$, just $2 \%$ less than the control larvae of the same age (data not shown). Balance was assessed at the same time by examining the ability of the larvae to stay dorsal side up for at least 1 min after the Petri dish was tapped. Our results showed that MO ${ }^{\text {tmie1 }}$ morphants showed delayed development of balance by about 1 day compared to the control larvae (data now shown), while only $6 \%$ of $\mathrm{MOs}^{\text {tmie }}$ morphants acquired balance control at 6d (Fig. 4C).

We performed RNA rescue experiments with 100 and $200 \mathrm{ng}$ tmie RNA to demonstrate the specificity of the effect of $\mathrm{MOs}^{\text {tmie }}$. Although we did not observe a full rescue of swimming behavior, there was improvement of both motor coordination (Fig. 4B) and balance (Fig. 4C) with RNA injection, especially with $100 \mathrm{ng}$ RNA. However, we observed defects in embryos with doses of RNA higher than $100 \mathrm{ng}$, indicating that a higher dose of RNA is toxic to the embryos.

\section{tmie and Development of the Zebrafish Inner Ear}

To investigate the development of the inner ear in the tmie morphants, we performed in situ hybridization using several inner ear markers, including $m s x-c, b m p 4, n k x 5.1$, eya1, Na, K-ATPase $\beta 1 a$, and Na, K-ATPase $\beta 2 b$. Expression patterns in the morphants were indistinguishable from those in controls (data not shown), suggesting that tmie knockdown has no gross effects on development of the associated structures. The basic helix-loop-helix proneural transcription factor gene, atonal homolog 1a (atoh1a) is ex- pressed in the developing sensory cells in the inner ear, in addition to the lateral line. The differentiation of neuromast hair cells is determined by the expression of atoh1a (Sarrazin et al., 2006). The expression pattern of atoh1a in the ear is the same in the controls and tmie morphants (data not shown).

To observe the detailed structures of the inner ear, we carried out confocal microscope studies. Embryos or larvae were stained with anti-acetylated tubulin antibody and Texas-redcoupled phalloidin for detection of kinocilia and stereocilia, respectively. The length and number of kinocilia in the cristae of the tmie morphants were comparable to those of controls at 3 dpf (Fig. 5A and B). Similar results were observed in the maculae (Fig. 5C and D).

However, the formation of semicircular canals was defective in the morphants at this stage. By this stage, the central bulges and the projections from the wall of the ear normally fuse to form the pillar of each semicircular canal as seen in normal control ears at 3 dpf (Fig. 5E; Waterman and Bell, 1984). In the morphant ears, the ventral bulge and the ventral projection had not contacted each other to form intact semicircular canals (Fig. 5F), suggesting that tmie participates in the formation of semicircular canals. This is unlikely to be due to the developmental delay seen in the morphant ears, since at $5 \mathrm{dpf}, 28 \%(\mathrm{n}=7)$ of tmie morphants still had pronounced defects in semicircular canals.

As the inner ear develops, the number of differentiated hair cells in the maculae of control embryos increases over time as shown with phalloidin staining (Fig. 5K). At $4 \mathrm{dpf}$, the number of phalloidin-labeled hair cells in 


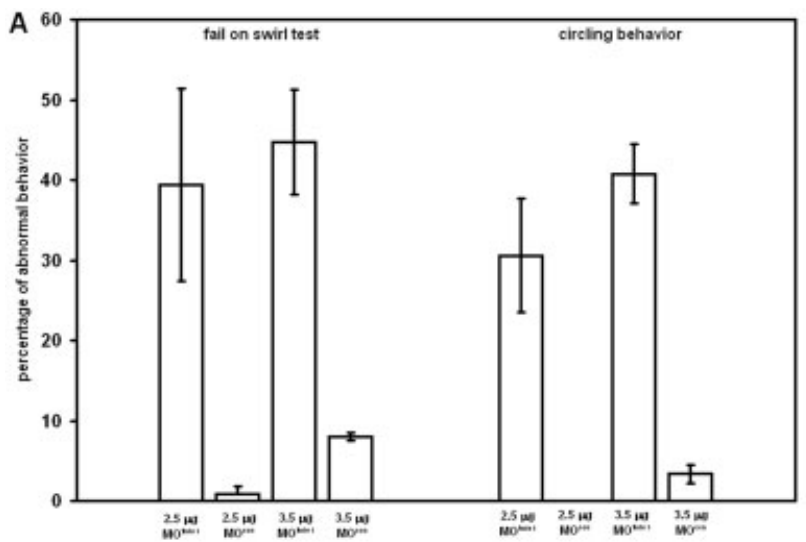

B

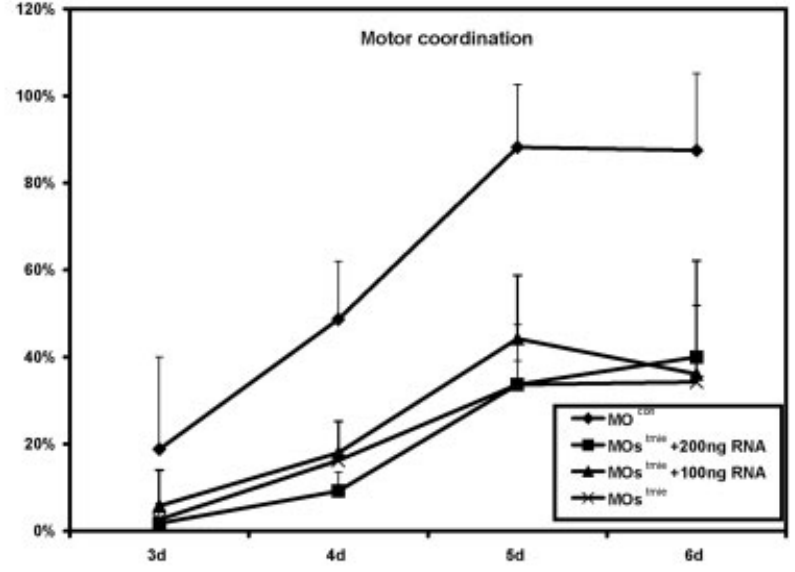

C

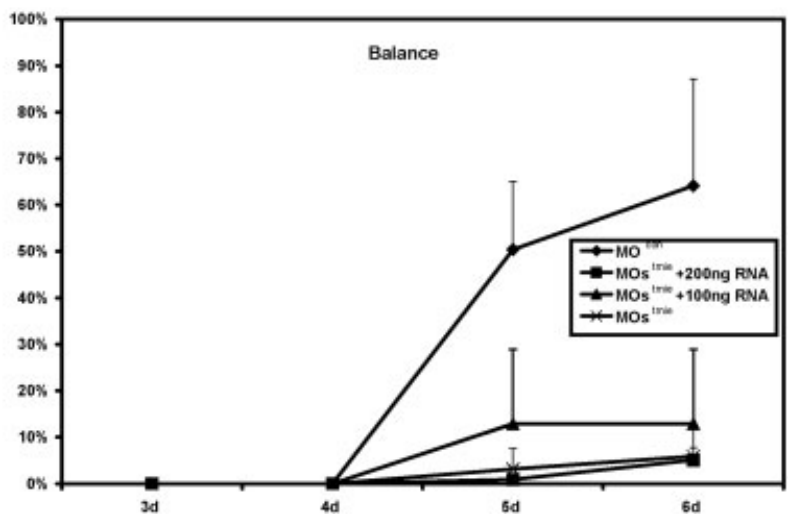

Fig. 4. Behavioral assessment of fish. A: Swirl test of embryos at $96 \mathrm{hpf}$ with $2.5 \mu \mathrm{g} / \mathrm{l}$ control MO $(\mathrm{n}=66), 2.5 \mu \mathrm{g} / \mathrm{l}$ MOtmie1 $(\mathrm{n}=293), 3.5 \mu \mathrm{g} / \mathrm{l}$ MOcon $(\mathrm{n}=45)$, and $3.5 \mathrm{~g} / \mathrm{l}$ MOtmie1 $(\mathrm{n}=152)$. Development of balance (B) and development of motor coordination (C) in control embryos (MOcon, $\mathrm{n}=113$ ), tmie morphants with $2.5 \mathrm{ng}$ of MOs $(\mathrm{n}=107)$, tmie morphants with $2.5 \mathrm{ng}$ MOs plus $100 \mathrm{ng}(\mathrm{n}=96)$ or $200 \mathrm{ng}(\mathrm{n}=90)$ tmie RNA. Data show the means and standard errors of two independent experiments.

the $\mathrm{MOs}^{\text {tmie }}$ morphants was slightly lower than the wild-type larvae, but there was no statistically significant difference between the two groups. The number of hair cells labeled with phalloidin in the $\mathrm{MOs}^{\text {tmie }}$ morphants also increased during the period of observation (4 to $6 \mathrm{dpf}$ ). However, the rate of increase in the number of labeled cells was much slower in the morphants than the control larvae so that at later stages, the number of hair cells with phalloidin-stained stereocilia in the anterior macula was significantly smaller in the morphants than in the control larvae (Fig. 5G-K). Due to the fact that the number was larger at later stages even in the morphants, it is possible that the total number of hair cells was smaller rather than that we were observing deterioration of the actin filaments in the hair bundles. The lengths of kinocilia in the posterior maculae of morphants was similar to that of the controls, indicating that the kinocilia had not degenerated in the morphants (Fig.5L-O).

\section{tmie and Development of the Posterior Lateral Line}

Due to the circular swimming behavior of the tmie morphants, we suspected that in addition to the inner ear pathology, the lateral line of these morphants might be compromised as well. DASPEI (4-(4-diethylaminostyryl)-N-methylpyridinium iodide), a vital mitochondria dye, was used to detect active hair cells in the neuromasts of the lateral line system (Bricaud et al., 2001). At 72 hpf, the posterior lateral line (PLL) contains five to six neuromasts on each side of the trunk, and three neuromasts on each side of the tail. The anterior lateral line (ALL) consists of about 11 neuromasts in the head area. In control embryos at this stage, the neuromasts in both the ALL and PLL were stained with DASPEI (Fig. 6A), indicating that these hair cells were electrically active. However, in the $\mathrm{MOs}^{\text {tmie }}$ morphants, no staining or only very dim staining was observed in at least $50 \%$ of the embryos at this stage (Fig. 6B), suggesting that no or few electrically active hair cells were present. However, at $5 \mathrm{dpf}$, the number of neuromasts in the PLL increased to 11-13 in the control larvae (Fig. 6C) as well as in some of the tmie morphants (Fig. $6 \mathrm{D})$, indicating that the hair cells were differentiated, mature, and active in these larvae and suggesting a delay in one or more of these processes due to the knockdown of tmie. To measure the average intensity of DASPEI staining after each treatment, we evaluated the DASPEI staining levels in the larvae at 4, 5, and $6 \mathrm{dpf}$ by a scoring mechanism described in the Experimental Procedures section. The higher the score (the closer it is to 2.0), the stronger the DASPEI labelling. In the control embryos, the scores were over 1.9 from $4 \mathrm{dpf}$ on, indicating that most of the embryos have strong DASPEI staining (Fig. 6M). However, the labelling score of $\mathrm{MOs}^{\text {tmie }}$ morphants 


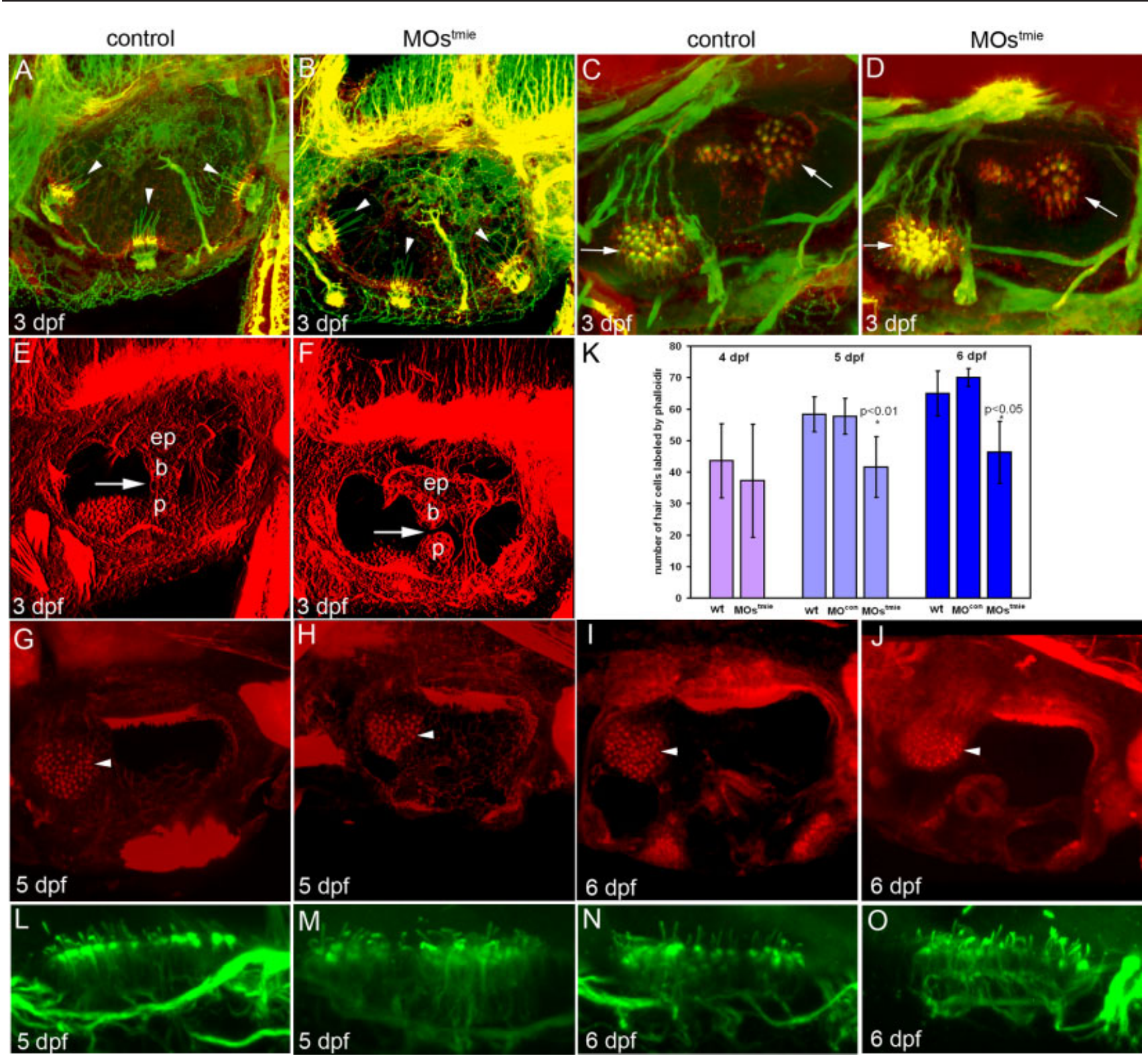

Fig. 5. Staining of actin (phalloidin staining, red) and acetylated tubulin (green) in hair cell patches in the inner ear showed defects in tmie morphants. A,B: Double staining of actin (stereocilia) and tubulin (kinocilia) of the three cristae (arrowheads). C,D: Double staining of stereocilia and cristae in the maculae (arrows). E,F: Actin staining showing the epithelial pillars (ep), which form hubs of the developing semicircular canals. Arrows indicate the junction of the ventral bulge (b) and ventral projection (p). In the control ear, the junction has formed and fused (E), but in the tmie MO-treated fish, there is still a gap between the bulge and the projection. G-J: Phalloidin staining of the anterior macula (arrowhead) at $5 \mathrm{dpf}(\mathrm{G}, \mathrm{H})$ and $6 \mathrm{dpf}(\mathrm{I}, \mathrm{J})$. The patch is smaller in tmie morphants, especially at $6 \mathrm{dpf}$. K: Numbers of hair cells labeled by phalloidin at $4 \mathrm{dpf}(\mathrm{n}=5$ for wt, and $\mathrm{n}=4 \mathrm{for} \mathrm{MOstmie})$, and as illustrated in $\mathrm{G}-\mathrm{H}$ at $5 \mathrm{dpf}(\mathrm{n}=3$ for wt, $\mathrm{n}=6$ for control, and $\mathrm{n}=13$ for MOstmie) and $6 \mathrm{dpf}(\mathrm{n}=2$ for wt, $\mathrm{n}=2$ for control, and $\mathrm{n}=4$ for MOstmie). L-O: Acetylated tubulin staining of the posterior macula.

was below 0.2 at $4 \mathrm{dpf}$, and only gradually increased to 0.8 at $6 \mathrm{dpf}$, indicating that most of the neuromast hair cells are still not active in these larvae. Although RNA injections did not fully restore the activity of neuromast hair cells, the higher scores seen in the "rescued" embryos (0.3 to 1.1 for $200 \mathrm{ng}, 0.4$ to 1.2 for $100 \mathrm{ng}$ RNA; Fig. $6 \mathrm{M})$ suggested that the neuromast $\mathrm{HCs}$ in RNA-treated embryos are more active than those of $\mathrm{MOs}^{\text {tmie }}$ morphants.

To determine whether the lack of DASPEI staining in 3-dpf morphants was due to a delayed migration of the lateral line primordium, delay of differentiation, or delayed maturation of the hair cells in the neuromasts, we performed in situ hybridization on whole mount embryos. Cxcr4b is the receptor for the chemokine sdf-1a, and $c x c r 4 b$ mRNA is normally detected in the migrating primordium of the PLL, so it serves as a good marker for the migrating primordium (David et al., 2002). A PLL primordium can first be detected posterior to the otic vesicle at $20 \mathrm{hpf}$, after which time it migrates caudally along the horizontal myoseptum, and reaches the tip of the tail by the end of the second day of development. Five proneuromasts are depos- 


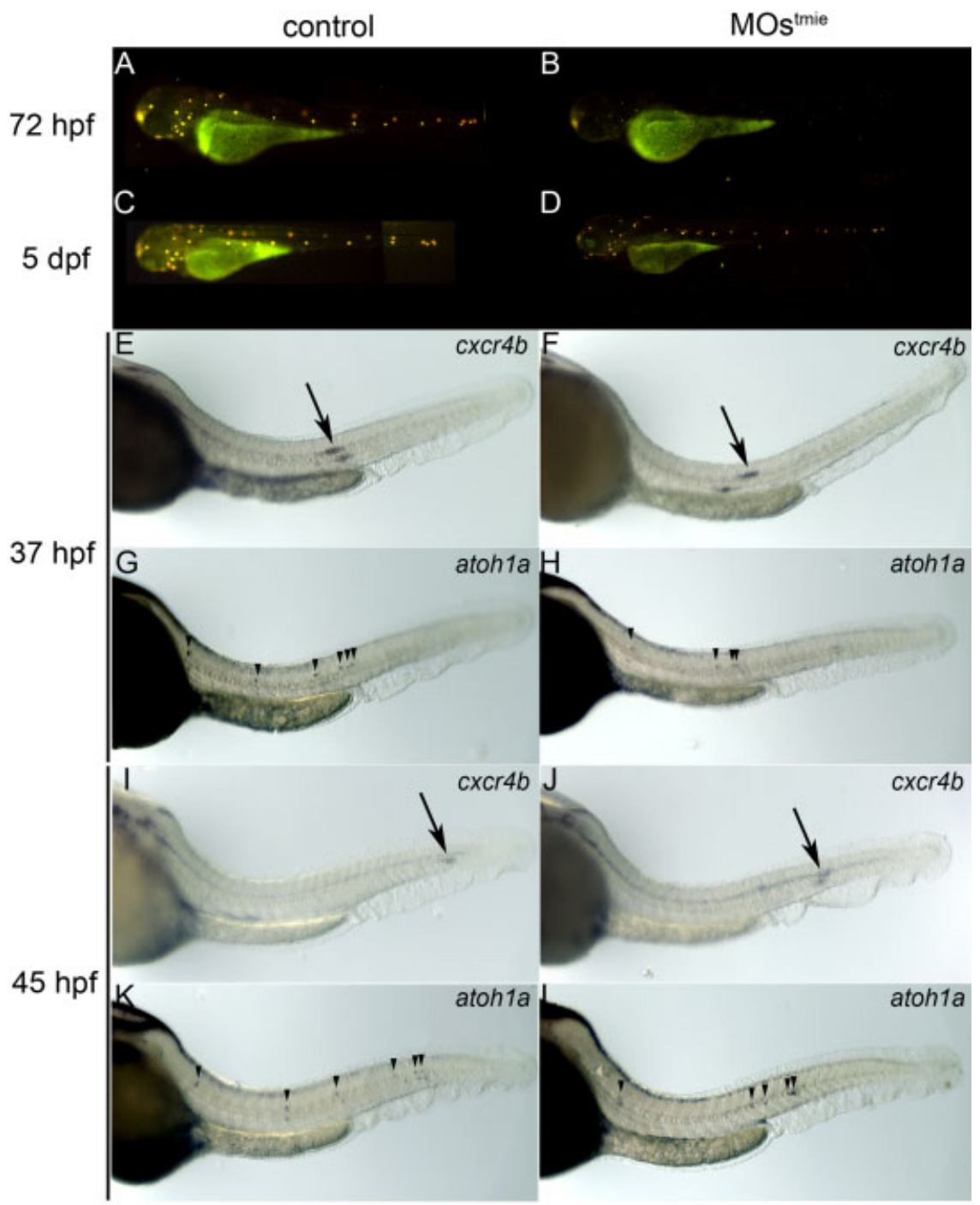

M

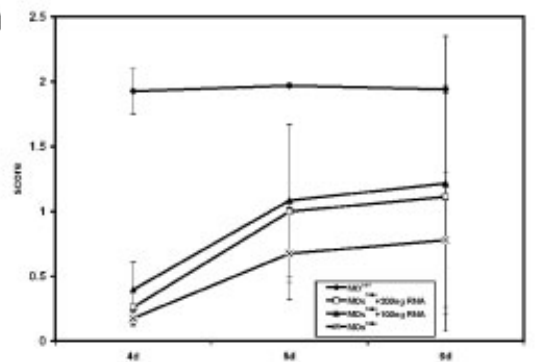

Fig. 6. The development of lateral line was affected in MOstmie morphants. A-D: DASPEl staining of lateral line neuromasts. There is no or very little staining in MOstmie at $72 \mathrm{hpf}(\mathbf{B})$ compared to the control $(\mathbf{A})$ at the same stage. The lateral staining is weaker at $5 \mathrm{hpf}$ in the MOstmie morphants (D) but present compared to the control larvae (C). E-L: Whole mount in situ hybridization with cxcr4b (E, F, I, J) and ath1 probes $(\mathbf{G}, \mathbf{H}, \mathbf{K}, \mathbf{L})$. Arrows, the migrating lateral line primordium. Arrowheads, the neuromasts with atoh1a signal. M: DASPEI score of the lateral line. After DASPEI staining, the larvae were divided into 3 groups: strongly stained, weakly stained, and not stained. Each fish was assigned a score after the level of staining in all the fish was first observed. Each larva in the strongly stained group was given 2 points, while 1 point was given to the weakly stained larvae, and 0 points to larvae, which were not stained. The number of fish in each group was recorded. The cumulative scores were then calculated and the percentage of fish in each group following each treatment determined. The higher the score (and the closer to 2.0), the stronger the staining of DASPEI observed after each treatment.

ited along the way as the primordium migrates. Each proneuromast differentiates after its deposition and becomes a mature neuromast in a few hours (Ghysen and Dambly-Chaudière, 2005). Our results showed that the migration of the PLL primordium was slightly, but not drastically, delayed in tmie morphants (Fig. 6E,F,I,J). The expression of atoh1a in the neuromasts of PLL in the morphants is comparable to that of the control embryos, although slightly delayed in its time of expression (Fig. 6G,H,K,L), suggesting that the hair cells differentiate normally in the morphants after the deposition of the proneuromasts, although there is a delay in acquiring electrical activity.

\section{DISCUSSION}

Based on our earlier studies of spinner mice carrying null mutations in Tmie, this gene has been implicated in the regulation of maturation of sensory hair cells and in maintaining the normal architecture of the stereocilia bundle (Mitchem et al., 2002). The identification of mutations in the human TMIE gene in individuals with profound, congenital hearing loss indicates a critical role for this gene in the human auditory system ( $\mathrm{Naz}$ et al., 2002). We have now identified a Tmie ortholog in zebrafish. The genomic structure and encoded protein of this tmie gene exhibit strong conservation with mammalian Tmie genes. Our analysis of tmie in zebrafish supports a role for this gene in the development and function of mechanoreceptor organs.

Expression of tmie was observed at 26,36 , and $51 \mathrm{hpf}$ in zebrafish, which are stages analogous to those of Tmie expression in mice. Labeling patterns with antisense probes indicated that there was significant although not robust tmie expression in zebrafish at 26 and $36 \mathrm{hpf}$, which was slightly reduced by $51 \mathrm{hpf}$. Labeling at 26 and 36 hpf was found in the epithelium of the inner ear, during the periods of otic vesicle and otolith formation. We also observed tmie expression in the brain. In mice, ISH studies of Tmie expression also failed to document robust expression of Tmie, and we were unable to document mouse Tmie by ISH, except with a radiolabelled probe (K.L.H. and D.C.K., unpublished ob- 
servations). We, therefore, used RTPCR studies to document Tmie expression in the mouse inner ear at early postnatal time points, consistent with the early onset of sensory hair cell pathology in spinner mutants (Mitchem et al., 2002; K.L.H. and D.C.K., unpublished results). These early defects in sensory cells in the mouse indicate that Tmie is required for proper maturation of sensory hair cells in the cochlea and in vestibular organs. While we could readily detect expression of tmie in several tissues, we were unable to detect its expression in the inner ear in zebrafish after the otocyst stage. Similar attempts to detect Tmie expression by in situ hybridization of inner ear tissue from postnatal mice have also been unsuccessful, suggesting that steady-state levels of the transcript may be relatively low later in ear development and, therefore, below the detection threshold of this approach. Zebrafish tmie is expressed in the brain in addition to the inner ear, similar to the broad expression patterns of the gene in mouse and humans, which include expression in the brain and in the eye (Mitchem et al., 2002; Naz et al., 2002). The precise role of tmie in these other tissues is unclear, as mice and humans carrying mutations in the gene do not appear to exhibit other associated pathologies. Most tmie MOinjected fish with small ears also had small eyes, and many with normal ears had at least one small eye, indicating a significant effect of the tmie morpholino on eye size (see Table 1). The broader pathology in tmie morphants suggests less genetic redundancy of tmie-associated pathways in zebrafish relative to those in mammals.

Our studies using morpholinos directed at blocking expression of normal tmie are consistent with an evolutionarily conserved role for this gene in inner ear function. We identified abnormalities in swimming behavior in tmie morphant fish, including exaggerated spontaneous circling and altered swimming after touch stimuli or dish swirling. These abnormal behaviors were associated with defects in mechanoreceptor morphology, including decreased inner ear size, reduced numbers of otoliths in vestibular organs, and alterations in lateral line functional maturation. These patholo- gies are likely to underlie the abnormal swimming behavior of the morphant fish, as abnormalities in the ear change perception of both balance and acceleration. The incomplete penetrance of the behavioral and morphological phenotypes, (e.g., 30\% swimming defects as opposed to $100 \%$ ) is presumably due to the incomplete knockdown of tmie, as evidenced by residual expression of normal tmie transcripts in the morphants.

In other published studies of zebrafish "circler" mutants, gross inner ear structures appeared normal but hair cells degenerated (Ashmore, 1998; Nicolson et al., 1998). Although the tmie morphants studied here differ in that there are obvious morphological defects, altered hair cell function may also contribute to the abnormal swimming behaviors. Our results showed that although the gross morphology of the inner ear was not affected with tmie knockdown, defects in semicircular canals were observed in the tmie morphants, indicating that tmie is required for formation of mature semicircular canals. In addition, at 5 and $6 \mathrm{dpf}$, the number of hair cells labeled with phalloidin in the anterior macula was significantly reduced in the tmie morphants relative to control larvae. There are at least three possible explanations for this result: first, the normal increase during development in the number of hair cells may fail to occur in tmie morphants; second, normal numbers of hair cells may be produced in the morphants, but fail to differentiate over time into fully mature hair cells, thus phalloidin staining failed to identify these cells; or third, the cells were produced and differentiated, but their stereociliar bundles deteriorated and hair cells degenerated, similar to the pathologies observed in spinner mice. Further studies are necessary to demonstrate the basis for fewer phalloidin-stained cells in tmie morphants. We have previously found that both cadherin-2 and cadherin-4 have a role in inner ear morphogenesis and that MOs to these genes affect many of the same parameters that are affected by tmie MOs (Babb-Clendenon et al., 2006; Wilson et al., 2007). The defects we observed in cadherin-2 morphants (Babb-Clendenon et al., 2006) are quite similar to those seen in tmie morphants. In both, the organization of the hair cell bundle was disrupted, and the formation of the semicircular canals was incomplete. Although they may both be transmembrane proteins, the downstream effector(s) of tmie have not been reported. It is possible that the cadherins and tmie share some common downstream molecules.

Our previous studies in the mouse suggested that the Tmie protein may reside in the internal membrane of sensory cells where it could influence protein trafficking pathways, or, alternatively, the protein may be localized to the plasma membrane where it could serve as an interaction site for other molecules (Mitchem et al., 2002). Since Tmie has already been found to participate in hair cell maturation and maintenance of the stereociliar architecture in mice, this could imply a role for the Tmie protein in organizing cytoskeletal arrangements of sensory hair cells, which would be consistent with the affected swimming behaviors of the tmie morpholino-injected fish.

The results of these experiments also implicated tmie in the process of hair cell maturation in the neuromasts of the posterior lateral line (PLL). In zebrafish, the migration of the primordium of the PLL to the tail starts at 20-22 hpf from the PLL placode, located at the hindbrain, just posterior to the otic placode. The migration is completed at about $48 \mathrm{hpf}$, and deposits 5 lateral proneuromasts along the trunk and 2-3 terminal proneuromasts at the tip of the tail in each side of the body (DamblyChaudière et al., 2003). These proneuromasts then differentiate during the next few hours, and about $6 \mathrm{hr}$ after deposition, some hair cells can be detected functionally with DASPEI (Gompel et al., 2001). In tmie morphants, although the migration of the PLL primordium was slightly delayed, a delay does not account for the lack of DASPEI staining at $72 \mathrm{hpf}$. In situ hybridization with an atoh1a probe showed that the hair cells differentiated soon after the deposition of proneuromasts, indicating that the early differentiation of the hair cells was not affected by tmie MOs. However, the maturation and/or the activity of the hair cells was substantially delayed or blocked in tmie morphants. 
The recovery of DASPEI staining at 5 dpf could be due to the degradation of tmie MOs over time, indicating that hair cells eventually became active after an earlier delay due to decreased tmie expression. However, HC regeneration or stereociliar regeneration are also possible explanations. No matter what the mechanism is, tmie function is required for the timely activity of the hair cells in the neuromasts in the lateral line.

The results in the RNA rescue experiments on recovery of swimming behavior and LL DASPEI staining showed that the effects of MOs ${ }^{\text {tmie }}$ on these functional aspects are specific, not due to the toxic effect of MOs.

The reductions in phalloidinstained hair cells in the inner ear, as well as the delayed hair cell activity in the lateral line of tmie morphants, suggests that tmie protein is likely to participate in maturation/function and probably maintenance of the hair cells in both organs involved in balance/swimming behavior. Further observation of the morphological and behavioral effects of the tmie morpholino on the inner ears and brain will provide greater insight into the role of tmie in the developing zebrafish and its effects on hair cells and sensory transduction. Further analysis of the specific expression patterns of tmie at various stages, the effects of more complete knockdown of the gene, and the interaction of tmie with other developmental genes is critical to understanding the role of this gene in mechanoreceptor dysfunction in zebrafish and humans.

\section{EXPERIMENTAL PROCEDURES}

\section{Zebrafish Maintenance, Embryo Collection, and Embryo Husbandry}

Zebrafish were obtained from a local pet store (University Aquarium, Ann Arbor, MI) or from the Zebrafish facility at the University of Oregon and kept on a 14:10 hr light/dark cycle at $28.5^{\circ} \mathrm{C}$. The embryos were collected 30-45 min after removing the dividers that separated the males and females in the mating tanks. All mating tanks were kept in a water bath at $28.5^{\circ} \mathrm{C}$. Embryos were raised in fil- tered methylene blue fish water, which prevents fungal growth on fish eggs ( $5 \%$ methylene blue to every 2 gallons fish water) at $28.5^{\circ} \mathrm{C}$. Between 12 and $20 \mathrm{hpf}, 0.03 \%$ 1-phenyl-2-thiourea (chemical formula $\mathrm{C}_{6} \mathrm{H}_{5} \mathrm{NaHCSNH}_{2}$ / PTU) was added at a 1:10 ratio to prevent pigmentation from developing. Embryos continued to grow overnight and then were fixed in $4 \%$ paraformaldehyde (PFA) in phosphate buffered saline (PBS; $1 \times$ PBS, $\mathrm{pH}$ 6.8) at the time/stage indicated, and kept at $4^{\circ} \mathrm{C}$ overnight. After several rinses with PBST $(0.1 \%$ Triton in $1 \times$ PBS), embryos were dehydrated in $\mathrm{MeOH}$ and stored at $-20^{\circ} \mathrm{C}$. These methods were adopted from The Zebrafish Book (Westerfield, 2000).

\section{tmie Gene Identification and RT-PCR Analysis}

The mouse Tmie protein sequence was used to search the zebrafish genome using the TBLASTN algorithm (Altschul et al., 1990). A significant match was identified with a region on chromosome 2. Primers corresponding to putative zebrafish exons were used to amplify the predicted transcript by reverse transcription-polymerase chain reaction (RT-PCR) from RNA prepared from 36-hpf zebrafish larvae. RNA was reverse-transcribed with the Superscript III system (Invitrogen). PCR was performed using Advantage Taq polymerase (BD BiosciencesClontech). RT-PCR products were gelpurified and directly sequenced as detailed previously (Burgess et al., 1995). A related gene was also similarly identified in genomic sequence from Fugu rubripes. Protein sequences encoded by the fish genes were compared to mammalian Tmie sequences using the CLUSTAL algorithm (Chenna et al., 2003). Putative transmembrane domains were identified using the TMHMM algorithm (Krogh et al., 2001). Zebrafish primers used in the RT-PCR analysis are as follows: F3 (5'-CTGCGCAGTTTTGTTTCGTCCAG-3'), R2 (5'-TGGCATAATTTTTCGCAGCAAGTCTTT-3'); F1 (5'-GGGACTTCGATTATGGCAGGTTGTG-3'), R6 (5'-TTTGCGGGTTCCTCTTTCTCCTCTTC-3'); F4 (5'"TCGCAGGAAAGGTGGACGGAGAA3'), R5 (5'"-GAACCGTGCAGCAGTGTTGTATTATTTAGTG-3'). The posi- tions of the primers used in these studies are illustrated in Figure 1A. To detect tmie transcripts at various developmental stages, total RNA was isolated from whole embryos. RT-PCR was performed using the F3/R6 primer pair with amplification conditions: $94^{\circ} \mathrm{C}, 5 \mathrm{~min}$; 35 cycles of $94^{\circ} \mathrm{C}, 30 \mathrm{sec}$; $60^{\circ} \mathrm{C}$, $30 \mathrm{sec} ; 72^{\circ} \mathrm{C}, 1 \mathrm{~min}$; final extension of $10 \mathrm{~min}$ at $72^{\circ} \mathrm{C}$. The predicted size of the RT-PCR products is $602 \mathrm{bp}$.

\section{In Situ Hybridization}

RT-PCR was used to amplify cDNA fragments for probe templates. RTPCR product derived from nucleotides 7-550 from the start codon of tmie was cloned into the pCRII-TOPO vector (Invitrogen Corp., Carlsbad, CA) and digested with either EcoRV or BamHI restriction enzymes to produce templates for sense and antisense probes, respectively. After column purification of digested template DNA (MinElute Reaction Cleanup kit, Qiagen Inc., Valencia, CA), synthesis was performed using a DIG RNA label, and T7 polymerase for sense and SP6 polymerase for antisense. Wholemount in situ hybridization was performed as previously described (Barthel and Raymond, 1990; Liu et al., 1999; Doudou et al., 2004; Babb-Clendenon et al., 2006). Hybridizations were detected using an alkaline-phosphatase-conjugated antibody and visualized with 4-nitroblue tetrazolium/ 5-bromo-4-chloro-3-indolyl phosphate (NBT/BCIP; Roche Molecular Biochemicals, Indianapolis, IN). The embryos were observed under a Leica FM10 stereo dissecting microscope and photos were taken by the attached Leica DC480 digital camera (Leica Microsystem Imaging Solution, Inc., Cambridge, UK) and processed by the Adobe Photoshop program.

\section{Morpholino Injections}

tmie morpholinos (Gene Tools, Corvallis, OR) were designed based on the genomic sequence of zebrafish tmie. One morpholino ( $\left.\mathrm{MO}^{\mathrm{tmie}} \mathbf{1}\right)$ was derived from sequence of the antisense strand at the exon 3/intron 3 boundary: 5' TAAGACTTGGACTCACCGCCGGGCA-3'. The other morpholino $\left(\mathrm{MO}^{\text {tmie2}}\right)$ was derived from sequence of the antisense strand at the exon 
2/intron 2 boundary: 5' ACACTTGCAGAAACTTACTTATTGC-3'. These MOs were injected at concentrations of 2.5 , 3.5 , and $5 \mu \mathrm{g} / \mu \mathrm{l}$. The concentration used with combined $\mathrm{MO}^{\text {tmie } 1}$ and $\mathrm{MO}^{\text {tmie2 }}\left(\mathrm{MOs}^{\text {tmie }}\right.$ ) was $2.5 \mu \mathrm{g} / \mu \mathrm{l}$ for each of the MOs. The control morpholino used was a standard scrambled nucleotide sequence from Gene Tools: 5'-CCTCTTACCTCAGTTACAATTTATA-3'. One hundred nanomoles of this control morpholino was reconstituted in $200 \mu \mathrm{l}$ of vital dye and diluted to the same total concentration as the experimental MOs used for injections in each experimental type. tmie morpholino-injected fish were compared with control MO-injected fish and fish that were either injected with phenol red dye or buffer or that were not injected. tmie MOs were microinjected into the yolk of one- to eight-cell stage embryos according to previously published protocols (Doudou et al., 2004; Babb-Clendenon et al., 2006).

Injection of zebrafish was done using a PV820 Pneumatic PicoPump from World Precision Instruments and an attached Nitrogen tank. Embryos and injection materials were prepared following the methods suggested in The Zebrafish Book (Westerfield, 2000) and performed according to our previously published procedures (Doudou et al., 2004; BabbClendenon et al., 2006). RNA prepared from injected embryos was converted to first-strand cDNA by reverse transcription with oligo $\mathrm{dT}$ primers, then amplified with primers F1 and R6 or F3 and R2 to evaluate the efficacy of knockdown with $\mathrm{MO}^{\text {tmie1 }}$ and $\mathrm{MO}^{\text {tmie2 }}$, respectively. Amplification products were gel-purified and directly sequenced to verify their exon content. F1 and R6 amplify a 353-bp product from RNA of control embryos and an additional 203-bp product that lacks exon 3 from RNA of $\mathrm{MO}^{\text {tmie } 1}$ morphants. F3 and R2 amplify a 405-bp product from RNA of control embryos and $\mathrm{MO}^{\text {tmie } 2}$ morphants. Amplification conditions: $97^{\circ} \mathrm{C}, 3 \mathrm{~min} ; 35$ cycles of $94^{\circ} \mathrm{C}, 30 \mathrm{sec} ; 60^{\circ} \mathrm{C}, 30 \mathrm{sec}$; $72^{\circ} \mathrm{C}$, $45 \mathrm{sec}$; final extension of $5 \mathrm{~min}$ at $72^{\circ} \mathrm{C}$. RT-PCR products were separated by size on $1.5 \%$ agarose gels and visualized by ethidium bromide fluorescence.

\section{Morphological and Behavioral Observations}

Observation of injected fish began at $24 \mathrm{hpf}$ and continued periodically until 6 dpf. Fish were observed under a dissecting or inverted microscope. Phenotypic characteristics noted included size of embryo, spontaneous movement of the tail, size of tail and somite orientation, size of ear compared to wild type, number of otoliths, size and orientation of the eyes, and size and shape of head and forebrain. Behavioral tests were conducted to observe swimming behavior, orientation in relation to a light from below in Petri dishes in which the fish were placed, and response to touch. Tail swiping or gentle head tapping with the flat side of a needle or small plastic probe was also done, as well as exposure to light and swirling of water surrounding the fish in a 100-mm plastic Petri dish on a dissecting microscope. Fish that appeared significantly affected were removed and placed separately in labeled 24-well plates. The development of a relative percentage of fish was stopped in $4 \%$ PFA at 24, 48, and $72 \mathrm{hpf}$ based on the number of fish surviving.

Vestibular functional analysis was performed according to Kwak et al. (2006). Motor coordination was assessed by a gentle touch of the tail. Larvae that rapidly traverse a $6-\mathrm{cm}$ Petri dish in a straight line were scored as positive. Each larva was tested three times and scored as negative if it failed all three trials. Balance was tested by the ability of larvae to rest with their dorsal sides up $1 \mathrm{~min}$ after a startle response was initiated by tapping the Petri dish. Each fish was tested three times and was scored as negative if it failed all three trials.

\section{Actin and Acetylated Tubulin Staining}

Embryos or larvae were in kept in $4 \%$ $\mathrm{PFA} / \mathrm{PBS}$ overnight at $4^{\circ} \mathrm{C}$, and rinsed in $\mathrm{PBS} / 1.5 \%$ Triton $\mathrm{X}-100$ for 2 days to help penetration and to dissolve otoliths. Embryos were subsequently incubated with anti-acetylated tubulin antibody (Sigma, 1:1,000) overnight at $4^{\circ} \mathrm{C}$. After several rinses in BDP $(1 \%$ bovine serum albumin, and 0.1 DMSO in $1 \times \mathrm{PBS}$ ), embryos were incubated with secondary antibody (FITC or Al- exa 388 anti-mouse IgG, 1:100) + 1:10 Texas red-phalloidin (Molecular Probes) overnight at $4^{\circ} \mathrm{C}$. After 2-hr rinses with frequent changes of $\mathrm{BDP}$, the embryos were viewed with an Olympus FV500 confocal microscope in the Diabetes Research and Training Laboratory Facility at the University of Michigan.

\section{Lateral Line Hair Cell Staining}

To label physiologically active hair cells in neuromasts, embryos or larvae were exposed to DASPEI (4-(4-Diethylaminostyryl)-1-methylpyridinium iodine, Sigma D-3418) solution prepared as follows: $5 \mathrm{mg}$ of DASPEI were dissolved in $100 \mathrm{ml}$ fresh embryo water (Westerfield, 2000), and embryos were incubated at $28^{\circ} \mathrm{C}$ for 30 min in the solution. After a 1-min rinse with embryo water, the embryos or larvae were observed under a Leica FM10 stereo dissecting microscope using a fluorescent channel (Absorption 405-446 nm, Beam splitter $460 \mathrm{~nm}$, and Emission at $475 \mathrm{~nm}$ ) and were divided into 3 groups: strongly stained, weakly stained, and not stained. Larvae in the strongly stained group were given 2 points, while 1 point was given to the weakly stained larvae, and 0 points to larvae that were not stained. The scores were then calculated and the percentage of fish in each group after each treatment was determined to calculate an average score for the population. The higher the score (the closer to 2.0), the stronger the DASPEI staining observed after each treatment.

\section{RNA Rescue Experiments}

The open reading frame of tmie was amplified using RT-PCR with the EcoRI and XbaI sites on the 5'end and 3 'end, respectively, and cloned into pCS2+ vector. Capped RNA was synthesized using a mMESSAGE mMACHINE Sp6 in vitro transcription kit (Ambion Inc., Austin, TX). RNA was diluted into $100-$ and $200-\mathrm{ng} / \mathrm{nl}$ aliquots, and injected into the same blastomere that was previously injected (within $15 \mathrm{~min}$ ) with $\mathrm{MOs}^{\text {tmie }}$.

\section{ACKNOWLEDGMENTS}

Kristina L. Hunker was formerly known as Kristina L. Mitchem and was the first author on the Tmie 
mouse study (Mitchem et al., 2002). We thank Drs. C. Duan, R. Cornell, M. Brand, J. Wegner, and M. Westerfield, for probes and plasmids. We thank Carrie Rheingans and Jaqueline McMillan, University of Michigan, for excellent technical assistance and Christopher Cooke, Dilip Pawar, Tori Melendez, Caitlin Roth, and Maria Xiang for fish care. Confocal images were acquired at the University of Michigan Diabetes Center Microscopy facility (sponsored by the NIH through P60-DK20572). This work was supported by grants from the DRF and the NIH to K.F.B. (NIH DC05939 and NIH DC04184 and a sub-account from J. Marrs, K.F. Barald, and Q. Liu, Indiana University Medical School, RO1 DC006436), the NIH to D.K. (NIH DC003049) as well as NIH postdoctoral training grant support to Y.-c. Shen and D. Thompson (T32 DC00011 University of Michigan). The confocal microscope work was performed in the Morphology and Image Analysis Core of the Michigan Diabetes Research and Training Center funded by NIH5P60DK20572 NIDDK.

\section{REFERENCES}

Altschul SF, Gish W, Miller W, Myers EW, Lipman DJ. 1990. Basic local alignment search tool. J Mol Biol 215:403-410.

Ashmore J. 1998. Mechanosensation: swimming round in circles. Curr Biol 8: R425-427.

Avraham KB, Raphael Y. 2003. Prospects for gene therapy in hearing loss. J Basic Clin Physiol Pharmacol 14:77-83.

Babb-Clendenon S, Shen YC, Liu Q, Turner KE, Mills MS, Cook GW, Miller CA, Gattone VH 2nd, Barald KF, Marrs JA. 2006. Cadherin-2 participates in the morphogenesis of the zebrafish inner ear. J Cell Sci 119:5169-5177.

Barald KF, Kelley MW. 2004. From placode to polarization: new tunes in inner ear development. Development 131:4119-4130.

Barthel LK, Raymond PA. 1990. Improved method for obtaining 3-microns cryosections for immunocytochemistry. J Histochem Cytochem 38:1383-1388.

Bever MM, Fekete DM. 2002. Atlas of the developing inner ear in zebrafish. Dev Dyn 223:536-543.

Bricaud O, Chaar V, Dambly-Chaudière C, Ghysen A. 2001. Early efferent innervation of the zebrafish lateral line. J Comp Neurol 434:253-261.

Burgess DL, Kohrman DC, Galt J, Plummer NW, Jones JM, Spear B, Meisler MH. 1995. Mutation of a new sodium channel gene, Scn8a, in the mouse mutant 'motor endplate disease'. Nat Genet 10:461-465.
Chenna R, Sugawara H, Koike T, Lopez R, Gibson TJ, Higgins DG, Thompson JD. 2003. Multiple sequence alignment with the Clustal series of programs. Nucleic Acids Res 31:3497-3500.

Dambly-Chaudière C, Sapede D, Soubiran F, Decorde K, Gompel N, Ghysen A. 2003. The lateral line of zebrafish: a model system for the analysis of morphogenesis and neural development in vertebrates. Biol Cell 95:579-587.

David NB, Sapede D, Saint-Etienne L, Thisse C, Thisse B, Dambly-Chaudière C, Rosa FM, Ghysen A. 2002. Molecular basis of cell migration in the fish lateral line: role of the chemokine receptor CXCR4 and of its ligand, SDF1. Proc Natl Acad Sci USA 99:16297-16302.

Doudou E, Barald KF, Postlethwait JH. 2004. Over-expression of Zic2a rescues ventralized zebrafish embryos. Zebrafish 1:239-257.

Eisen MD, Ryugo DK. 2007. Hearing molecules: contributions from genetic deafness. Cell Mol Life Sci 64:566-580.

Friedman TB, Griffith AJ. 2003. Human nonsyndromic sensorineural deafness. Annu Rev Genomics Hum Genet 4:341402.

Fritzsch B, Silos-Santiago I, Bianchi LM, Farinas I. 1997. The role of neurotrophic factors in regulating the development of inner ear innervation. Trends Neurosci 20:159-164.

Ghysen A, Dambly-Chaudière C. 2005. The three-sided romance of the lateral line: glia love axons love precursors love glia. Bioessays 27:488-494

Gompel N, Cubedo N, Thisse C, Thisse B, Dambly-Chaudière C, Ghysen A. 2001. Pattern formation in the lateral line of zebrafish. Mech Dev 105:69-77.

Haddon C, Lewis J. 1996. Early ear development in the embryo of the zebrafish, Danio rerio. J Comp Neurol 365:113-128.

Kerber KA. 2006. The genetics of vertigo. Semin Neurol 26:484-491.

Krogh A, Larsson B, von Heijne G, Sonnhammer EL. 2001. Predicting transmembrane protein topology with a hidden Markov model: application to complete genomes. J Mol Biol 305:567-580.

Kwak SJ, Vemaraju S, Moorman SJ, Zeddies D, Popper AN, Riley BB. 2006. Zebrafish pax5 regulates development of the utricular macula and vestibular function. Dev Dyn 235:3026-3038.

Liu Q, Marrs JA, Raymond PA. 1999. Spatial correspondence between R-cadherin expression domains and retinal ganglion cell axons in developing zebrafish. J Comp Neurol 410:290-302.

Mitchem KL, Hibbard E, Beyer LA, Bosom K, Dootz GA, Dolan DF, Johnson KR, Raphael Y, Kohrman DC. 2002. Mutation of the novel gene Tmie results in sensory cell defects in the inner ear of spinner, a mouse model of human hearing loss DFNB6. Hum Mol Genet 11:1887-1898.

Naz S, Giguere CM, Kohrman DC, Mitchem KL, Riazuddin S, Morell RJ, Ramesh A, Srisailpathy S, Deshmukh D, Riazuddin S, Griffith AJ, Friedman TB, Smith RJ, Wilcox ER. 2002. Mutations in a novel gene, TMIE, are associated with hearing loss linked to the DFNB6 locus. Am J Hum Genet 71:632-636.

Nicolson T. 2005. The genetics of hearing and balance in zebrafish. Annu Rev Genet 39:9-22.

Nicolson T, Rusch A, Friedrich RW, Granato M, Ruppersberg JP, NussleinVolhard C. 1998. Genetic analysis of vertebrate sensory hair cell mechanosensation: the zebrafish circler mutants. Neuron 20:271-283.

Novince ZM, Azodi E, Marrs JA, Raymond PA, Liu Q. 2003. Cadherin expression in the inner ear of developing zebrafish. Gene Expr Patterns 3:337-339.

Piatto VB, Nascimento EC, Alexandrino F Oliveira CA, Lopes AC, Sartorato EL, Maniglia JV. 2005. Molecular genetics of non-syndromic deafness. Rev Bras Otorrinolaringol (Engl Ed) 71:216-223.

Platt C. 1993. Zebrafish inner ear sensory surfaces are similar to those in goldfish. Hear Res 65:133-140.

Santos RL, El-Shanti H, Sikandar S, Lee K, Bhatti A, Yan K, Chahrour MH, McArthur N, Pham TL, Mahasneh AA, Ahmad W, Leal SM. 2006. Novel sequence variants in the TMIE gene in families with autosomal recessive nonsyndromic hearing impairment. J Mol Med 84:226-231.

Sarrazin AF, Villablanca EJ, Nunez VA, Sandoval PC, Ghysen A, Allende ML. 2006. Proneural gene requirement for hair cell differentiation in the zebrafish lateral line. Dev Biol 295:534-545.

Strutz-Seebohm N, Seebohm G, Fedorenko O, Baltaev R, Engel J, Knirsch M, Lang F. 2006. Functional coassembly of KCNQ4 with KCNE-beta- subunits in Xenopus oocytes. Cell Physiol Biochem 18:57-66.

Torres M, Giraldez F. 1998. The development of the vertebrate inner ear. Mech Dev 71:5-21.

Waterman RE, Bell DH. 1984. Epithelial fusion during early semicircular canal formation in the embryonic zebrafish, Brachydanio rerio. Anat Rec 210:101-114.

Westerfield M. 2002. The zebrafish book. A guide for the laboratory use of zebrafish (Danio rerio). Eugene, OR: University of Oregon Press.

Whitfield T. 2000. The zebrafish anatomical dictionary. Entry on the inner ear, sensory patches, hair cells, semicircular canals, otoliths, statoacoustic ganglion and lateral line. In ZFIN. Available at: http://zfin.org/ zf info/anatomy/dict/current.html.

Whitfield TT. 2002. Zebrafish as a model for hearing and deafness. $J$ Neurobiol 53:157-171

Whitfield TT, Riley BB, Chiang MY, Phillips B. 2002. Development of the zebrafish inner ear. Dev Dyn 223:427-458.

Whitfield TT. 2005. Lateral line: precocious phenotypes and planar polarity. Curr Biol 15:R67-R70.

Wilson AL, Shen YC, Babb-Clendenon SG, Rostedt J, Liu B, Barald KF, Marrs JA, Liu Q. 2007. Cadherin-4 plays a role in the development of zebrafish cranial ganglia and lateral line system. Dev Dyn 236:893-902. 